\title{
SOX6 is downregulated in osteosarcoma and suppresses the migration, invasion and epithelial-mesenchymal transition via TWIST1 regulation
}

\author{
ZHENG WANG ${ }^{1}, \mathrm{JUNJIE} \mathrm{LI}^{1}, \mathrm{KUN} \mathrm{LI}^{2}$ and JIANJUN XU ${ }^{1}$ \\ Departments of ${ }^{1}$ Hand and Foot Surgery, and ${ }^{2}$ Oncology and Hematology, Changyi \\ People's Hospital, Changyi, Shandong 261300, P.R. China
}

Received August 11, 2017; Accepted December 20, 2017

DOI: $10.3892 / \mathrm{mmr} .2018 .8681$

\begin{abstract}
Transcription factor SOX6 (SOX6) has been reported to serve essential roles in numerous types of cancers. However, the expression and functions of SOX6 in osteosarcoma (OS) have not been analyzed. In the present study, the patterns of SOX6 expression in OS cell lines and tissues were investigated by reverse transcription-quantitative polymerase chain reaction and western blotting. The results of the present study revealed that SOX6 was notably downregulated in OS tissues and cell lines. Subsequently, gain- and loss-of-function studies demonstrated that SOX6 inhibited OS cell migration and invasion. In addition, SOX6 may have suppressed epithelial-mesenchymal transition via twist-related protein 1 (TWIST1) modulation. Chromatin immunoprecipitation (ChIP), quantitative ChIP and dual luciferase activity assays were used to confirm the binding of SOX6 to the promoter region of TWIST1. Additionally, colony formation assays and Cell Counting Kit- 8 assays demonstrated that SOX6 suppressed cell proliferation. The findings of the present study indicated that SOX6 serves as a tumor suppressor in OS and may be a potential therapeutic target for OS.
\end{abstract}

\section{Introduction}

Osteosarcoma (OS) is characterized by the production of immature or osteoid bone, which is derived from mesenchymal cells and has been become the most common type of malignant bone tumor (1-3). OS frequently occurs in children and young adults (4). Previous studies have suggested that OS possesses high metastatic potential; $\sim 80 \%$ of the metastases arise in bone, lung and lymph nodes (5-7). At present, OS treatment has significantly advanced, with options including

Correspondence to: Dr Jianjun Xu, Department of Hand and Foot Surgery, Changyi People's Hospital, 636 Limin Street, Changyi, Shandong 261300, P.R. China

E-mail: rzrtzb@sina.com

Key words: transcription factor SOX6, epithelial-mesenchymal transition, migration, invasion, proliferation, osteosarcoma chemotherapy, radiotherapy and surgery; the survival rate of patients with non-metastatic OS has improved by $60-70 \%$ (8), although the 5-year survival rate of patients with OS exhibiting lung metastasis remains low (9-14). Therefore, it is essential to identify the molecular mechanisms of OS.

Transcription factor SOX (SOX) family proteins contain a highly conserved high-mobility group (HMG) domain, which regulates their capacity for DNA binding (15-17). Based on the sequences of the HMG domains, SOX proteins are classified into groups A-H $(15,16)$. In addition, SOX proteins are expressed in several cell lineages, and serve essential roles in the differentiation of developing tissues and cell fate determination. Depending on the target sequences and interacting partners, SOX proteins may act as transcriptional repressors or activators to regulate the expression of various genes (17). SOX6 belongs to the D group and recognizes the $(\mathrm{A} / \mathrm{T})(\mathrm{A} / \mathrm{T})$ $\mathrm{CAA}(\mathrm{A} / \mathrm{T})$ highly conserved sequence. Previous studies have demonstrated that SOX6 serves tumor-suppressive functions in various human malignancies, including hepatocellular carcinoma $(18,19)$, esophageal squamous cell carcinoma (20) and chronic myeloid leukemia (21). Additionally, SOX6 serves different roles in different types of cancer; for example, SOX6 transcriptionally activates suppressor of cytokine signaling 3 (SOCS3) in primary erythroid cells (21). SOX6 transcriptionally suppresses cyclin D1 in pancreatic $\beta$-cells (22); however, the underlying mechanisms of the role of SOX6 in OS requires further investigation.

In the present study, the expression levels of SOX6 were downregulated in $\mathrm{OS}$, which was associated with tumor size, metastasis and poor prognosis of OS; SOX6 additionally suppressed cell proliferation. In OS, SOX6 acts as tumor suppressor and inhibits cell migration, invasion and epithelial-mesenchymal transition (EMT) via transcriptional regulation of TWIST1.

\section{Materials and methods}

Cell lines and cell culture. The human immortalized osteoblast cell line hFOB1.19 and human OS cell lines MG-63 and U2OS were purchased from the American Type Culture Collection (Manassas, VA, USA). MG-63 and U2OS cells were cultured in RPMI 1640 (HyClone; GE Healthcare Life Sciences, Logan, 

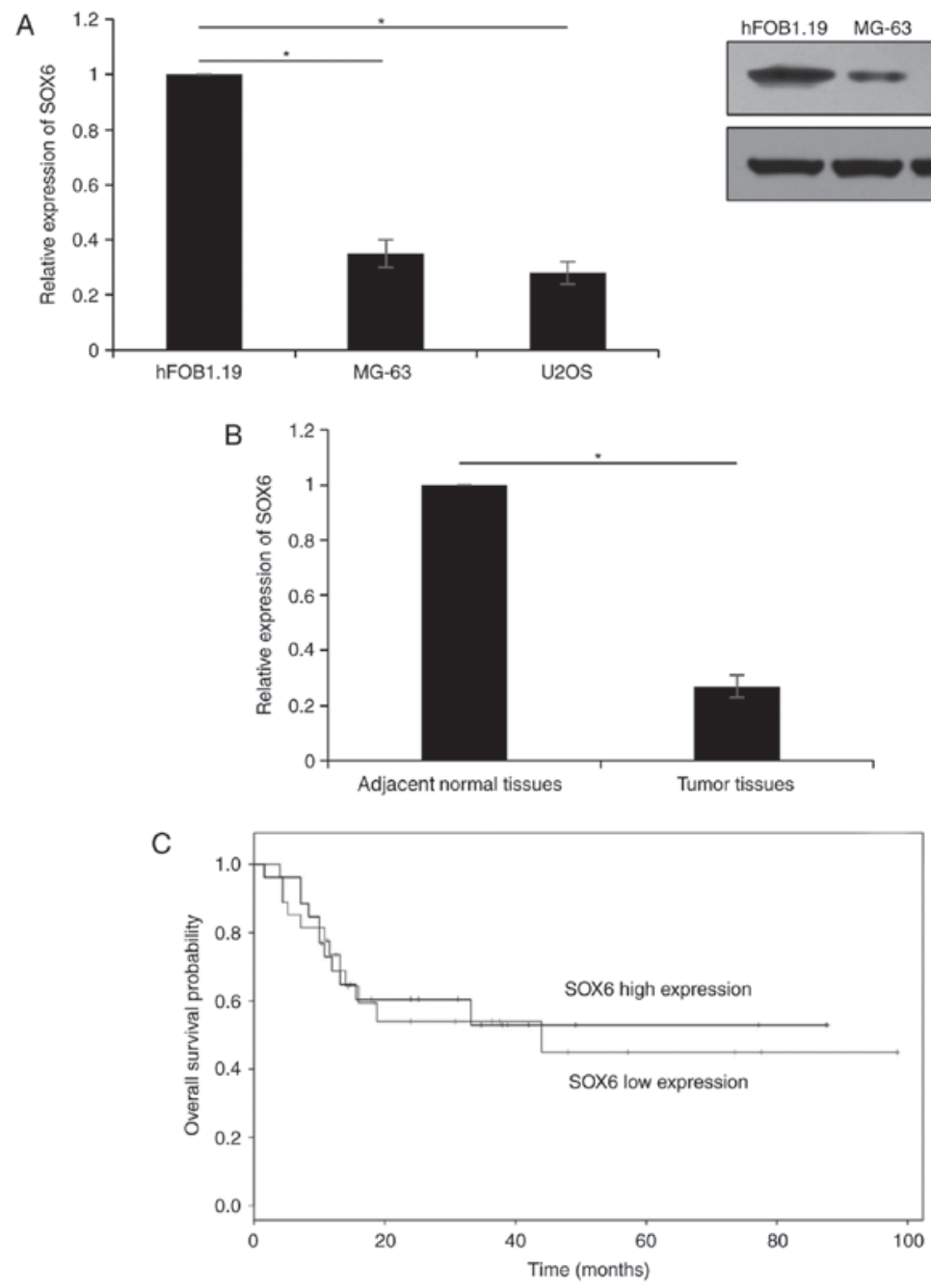

Figure 1. SOX6 is frequently upregulated in OS tissues and cell lines. (A) The expression of SOX6 in human osteosarcoma cell lines, MG-63 and U2OS, and the normal osteoblastic cell line, hFOB 1.19, were detected via RT-qPCR and western blotting. (B) The expression of SOX6 in OS tissues and adjacent normal tissues were detected using RT-qPCR. (C) The correlation between SOX6 expression and survival was estimated by Kaplan-Meier analysis and log-rank test. ${ }^{\text {*P }}<0.05$. OS, osteosarcoma; RT-qPCR, reverse transcription-quantitative polymerase chain reaction; SOX6, transcription factor SOX6.

UT, USA) supplemented with $10 \%$ fetal bovine serum (FBS; Sigma-Aldrich; Merck KGaA, Darmstadt, Germany) at $37^{\circ} \mathrm{C}$ with $5 \% \mathrm{CO}_{2}$. hFOB1.19 cells were cultured in Dulbecco's modified Eagle's medium (DMEM)/Ham's F-12 (HyClone; GE Healthcare Life Sciences) supplemented with $10 \%$ FBS and geneticin $(400 \mathrm{mg} / \mathrm{ml})$ at $34^{\circ} \mathrm{C}$ with $5 \% \mathrm{CO}_{2}$.

Cell transfection. For transfection with the pcDNA3.1-SOX6 plasmid, cells were cultured to $60-70 \%$ confluence, and transfected with $2.5 \mu \mathrm{g}$ vector (pcDNA3.1) or pcDNA3.1-SOX6 (YouBio, Hunan, China) using the polyethylenimine reagent (Thermo Fisher Scientific, Inc., Waltham, MA, USA), according to the manufacturer's protocol. For transfection with SOX6 small interfering (si)RNA, cells were cultured to $30-40 \%$ confluence, and transfected with $5 \mu \mathrm{l}$ scramble siRNA or SOX6 siRNA (Sigma-Aldrich; Merck KGaA) using the Lipofectamine ${ }^{\circledR} 2000$ reagent (Invitrogen; Thermo Fisher Scientific, Inc.), according to the manufacturer's protocol. The sequence of SOX6 siRNA as follows: SOX6 siRNA\#1: 5'-GGA AGAGACUUACGAAUUAGA-3', SOX6 siRNA\#2: 5'-GGAUCUCGCUGGAAAUCAAUG-3'. The more efficient sequence was subsequently selected for further experiments.
A total of $48 \mathrm{~h}$ following transfection, cells were collected and used for subsequent experiments.

Tissue specimens. OS tissues and adjacent normal tissues were obtained from patients who were diagnosed with OS between May 2013 and August 2016. All patients received no treatment with radiotherapy or chemotherapy prior to surgical excision; tissue samples were immediately frozen in liquid nitrogen prior to use. The present study was approved by the institutional ethics committee of Changyi People's Hospital (Shandong, China) and written informed consent was obtained from patients.

Cell counting kit-8 (CCK-8) assay. A CCK-8 assay (Dojindo Molecular Technologies, Inc., Kumamoto, Japan) was used to detect cell proliferation. Briefly, a total of $3 \times 10^{3}$ treated cells were suspended in $200 \mu \mathrm{l}$ DMEM and placed into a 96-well plate; $20 \mu \mathrm{l}$ CCK-8 solution was added to each well and cells were cultured at $37^{\circ} \mathrm{C}$ for $60 \mathrm{~min}$. The optical density was measured at $450 \mathrm{~nm}$ using a spectrophotometer (SpectraMax 190; Molecular Devices, Sunnyvale, CA, USA). All assays were performed in triplicate. 
Reverse transcription-quantitative polymerase chain reaction (RT-qPCR) analysis. RNA was isolated from cells and tumor specimens using an EasyPure RNA kit (Transgen Biotech Co., Ltd. Beijing, China), according to the manufacturer's protocol. RT was performed using EasyScript First-Strand cDNA Synthesis SuperMix (Transgen Biotech Co., Ltd) at $25^{\circ} \mathrm{C}$ for $10 \mathrm{~min}, 42^{\circ} \mathrm{C}$ for $15 \mathrm{~min}$ and $85^{\circ} \mathrm{C}$ for $3 \mathrm{~min}$, followed by cooling at $4^{\circ} \mathrm{C}$. RT-qPCR was performed with the SYBR Premix Ex Taq ${ }^{\mathrm{TM}}$ (Takara Bio, Inc., Otsu, Japan) using the Thermal Cycler Dice Detection System (Takara Bio, Inc.). GAPDH was used as an internal control. The relative expression level of genes was measured using the $2^{-\Delta \Delta \mathrm{Cq}}$ method (23). The following primer sequences were used: SOX6 forward, 5'-CСТCTACCTCACCACATAAGC-3'; reverse, 5'-TCCACC ACATCGGCAAGA-3'. E-cadhein forward, 5'-CCTCGAACT ATATTCTTCTGTGAG-3'; reverse, 5'-TAGATTCTTGGG TTGGGTCG-3'. $\alpha$-catenin forward, 5'-TGTTACACAGGT TACAACCCT-3'; reverse, 5'-GCAGCCTTCATCAAATCA CC-3'. N-cadherin forward, 5'-GTCATCACAGTGACAG ATGTC-3'; reverse, 5'-TTCAAAGTCGATTGGTTTGACC-3'. Fibronectin forward, 5'-CCGAACAGA AAT TGACAA ACCA-3'; reverse, 5'-CTTTAGGGCGATCAATGTTGG-3'. GAPDH forward, 5'-TCTCTGATTTGGTCGTATTGG-3'; reverse, 5'-CATGTAAACCATGTAGTTGAGGTC-3'.

Western blotting. Cells were harvested and lysed using radioimmunoprecipitation assay buffer supplemented with a protein inhibitor cocktail (Roche Diagnostics GmbH, Mannheim, Germany) for $30 \mathrm{~min}$ on ice, and centrifuged at 18,000 x g for $10 \mathrm{~min}$ at $4^{\circ} \mathrm{C}$. Protein concentration was measured using a Bicinchoninic Acid kit (Thermo Fisher Scientific, Inc.), according to the manufacturer's protocol. A total of $45 \mu \mathrm{g}$ protein lysate was separated via 10\% SDS-PAGE and transferred onto a nitrocellulose filter membrane. Following blocking with 5\% skimmed milk at room temperature for $1 \mathrm{~h}$, the membranes were incubated with the indicated primary antibody at $4^{\circ} \mathrm{C}$ overnight and with horseradish-peroxidase-conjugated secondary antibodies at room temperature for $1 \mathrm{~h}(1: 5,000$; Abcam, Cambridge, MA, USA; cat. nos. 6728 and 6721). The blots were visualized with an enhanced chemiluminescence kit (Beyotime Institute of Biotechnology, Haimen, China). All assays were performed in triplicate. The primary antibodies were as follows: SOX6 (1:3,000; cat. no. 64946; Abcam); $\beta$-actin (1:5,000; cat. no. 8226; Abcam), EMT kit (1:1,000; cat. no. 9782; Cell Signaling Technology, Danvers, MA, USA).

Wound healing assay. Treated cells $\left(\sim 1 \times 10^{6}\right)$ were placed into 6 -well plates, and the cell monolayer was gently scratched with a $20 \mu \mathrm{l}$ pipette tip when cells were cultured to $90-100 \%$ confluence. The cells were washed with cold PBS three times to remove the detached cells. Wound healing capacity was evaluated via the ratio of wounded area at the time points of 48 and $0 \mathrm{~h}$ post-scratching. All assays were performed in triplicate.

Transwell assays. A Transwell assay was performed to estimate the effect of SOX6 on cell invasion. A total of $100 \mu \mathrm{l}$ Matrigel (BD Biosciences, Franklin Lakes, NJ, USA) was coated on the top chambers $(6.5 \mathrm{~mm}$ diameter, $8 \mu \mathrm{m}$ pore size; Corning Incorporated, Corning, NY, USA) and incubated at $37^{\circ} \mathrm{C}$ for $30 \mathrm{~min}$. Subsequently, a total of $3 \times 10^{4}$ cells were
Table I. Clinical pathological variables in 42 patients with osteosarcoma.

\begin{tabular}{|c|c|c|c|c|}
\hline \multirow[b]{2}{*}{ Variables } & \multirow[b]{2}{*}{$\begin{array}{l}\text { Total } \\
(n=42)\end{array}$} & \multicolumn{2}{|c|}{$\begin{array}{l}\text { SOX6 protein } \\
\text { expression }\end{array}$} & \multirow[b]{2}{*}{ P-value } \\
\hline & & $\begin{array}{c}\text { Low } \\
(n=28)\end{array}$ & $\begin{array}{l}\text { High } \\
(n=14)\end{array}$ & \\
\hline \multicolumn{5}{|l|}{ Gender } \\
\hline Male & 22 & 15 & 7 & 0.827 \\
\hline Female & 20 & 13 & 7 & \\
\hline \multicolumn{5}{|l|}{ Age, years } \\
\hline$<20$ & 25 & 16 & 9 & 0.657 \\
\hline$\geq 20$ & 17 & 12 & 5 & \\
\hline \multicolumn{5}{|l|}{ Tumor size } \\
\hline$\geq 5 \mathrm{~cm}$ & 28 & 22 & 6 & 0.021 \\
\hline$<5 \mathrm{~cm}$ & 14 & 6 & 8 & \\
\hline \multicolumn{5}{|l|}{ Differentiation } \\
\hline Well/moderate & 20 & 14 & 6 & 0.662 \\
\hline Poor & 22 & 14 & 8 & \\
\hline \multicolumn{5}{|l|}{ TNM stage } \\
\hline I-II & 20 & 9 & 11 & 0.005 \\
\hline III-IV & 22 & 19 & 3 & \\
\hline \multicolumn{5}{|l|}{ Metastasis } \\
\hline Yes & 22 & 18 & 4 & 0.029 \\
\hline No & 20 & 10 & 10 & \\
\hline
\end{tabular}

suspended in $600 \mu \mathrm{l}$ serum-free RPMI-1640 and placed to the upper chamber. A total of $600 \mu 1$ RPMI-1640 containing $10 \%$ FBS was added to the lower chamber. Following $18 \mathrm{~h}$ of incubation at $37^{\circ} \mathrm{C}$ with $5 \% \mathrm{CO}_{2}$, the invaded cells were fixed with $4 \%$ paraformaldehyde at room temperature for $10 \mathrm{~min}$ and stained with $0.5 \%$ crystal violet at room temperature for $10 \mathrm{~min}$. The cells on the top membranes were removed with a cotton swab and the number of invaded cells was counted with a light microscope (five fields randomly selected). All assays were performed in triplicate.

Chromatin immunoprecipitation (ChIP) and quantitative ChIP (qChIP) assays. The U2OS cells were fixed with $1 \%$ formaldehyde, followed by numerous intervals of sonication (20 kHz, amplitude setting, 40\%; 20 cycles, $1 \mathrm{sec}$ on and $1 \mathrm{sec}$ off). For ChIP, the immunoprecipitated DNA fragments were quantified by PCR. The following thermocycling conditions were used for PCR: Initial denaturation for $2 \mathrm{~min}$ at $98^{\circ} \mathrm{C}$; 30 cycles of $98^{\circ} \mathrm{C}$ for $30 \mathrm{sec}, 58^{\circ} \mathrm{C}$ for $30 \mathrm{sec}$ and $72^{\circ} \mathrm{C}$ for $1 \mathrm{~min}$. The following primer sequences were used: Twistl forward, 5'-CGAGATGAGACATCACCCAC-3'; reverse, 5'-TAACAA TTCGTCCTCCCAAA-3'; Snail forward, 5'-GTTCTGCCC TTCAGGTTGGT-3'; reverse, 5'-AGGCTGTAACACGGC TCCAT-3'; Slug forward, 5'-ACTACCAGCAAATAAATA CC-3'; reverse, 5'-AACTGGAACCTGGAGTAAAA-3'. For qChIP, the immunoprecipitated DNA fragments were quantified by qPCR. The following thermocycling conditions were used: Initial denaturation for $5 \mathrm{~min}$ at $95^{\circ} \mathrm{C} ; 30$ cycles of $95^{\circ} \mathrm{C}$ for 

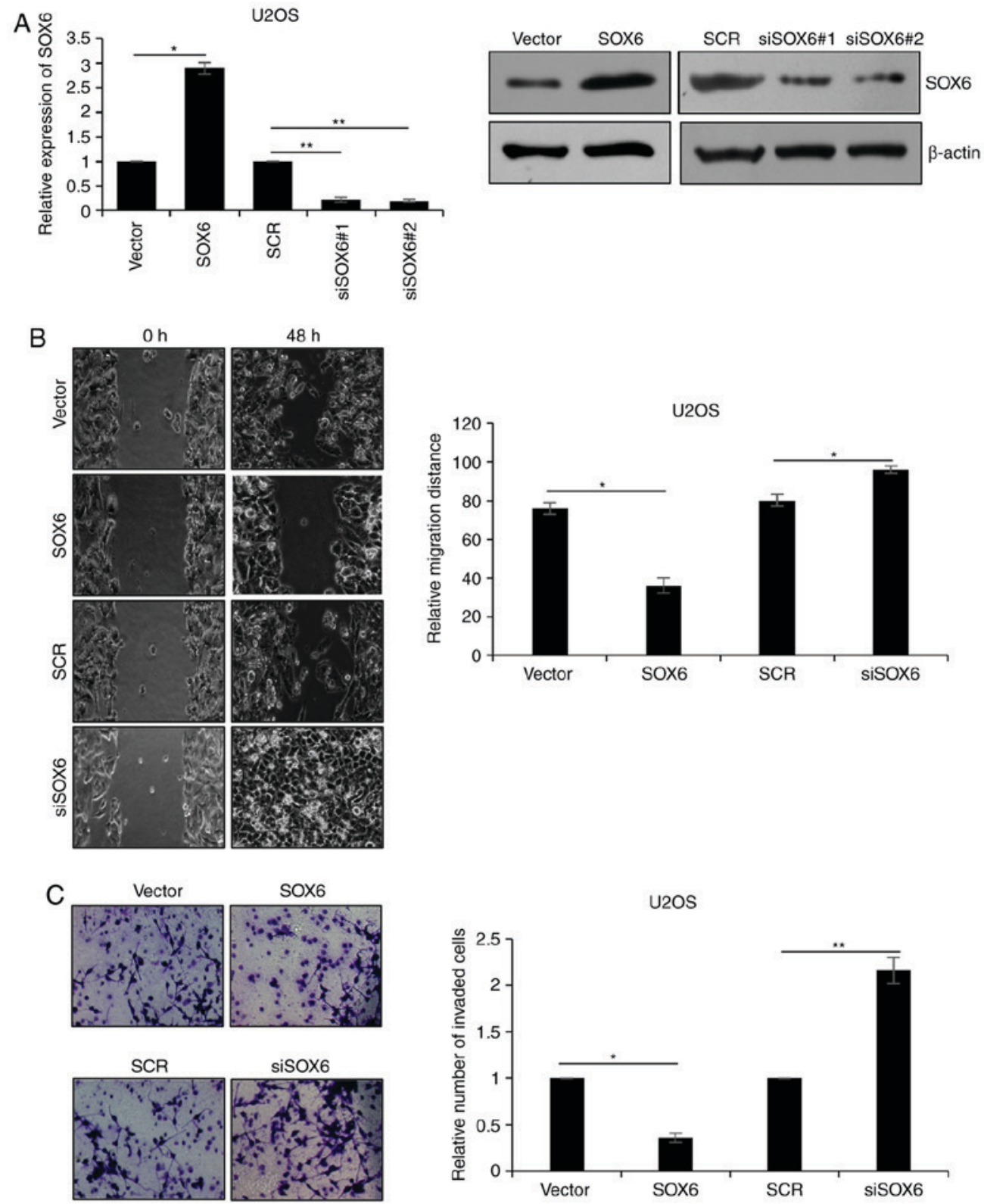

Figure 2. Downregulation of SOX6 facilitates migration and invasion in U2OS cells. (A) U2OS cells were transfected with vector or pcDNA3.1-SOX6, SCR or SOX6 siRNA \#1 and \#2, respectively. Following transfection for $48 \mathrm{~h}$, the mRNA and protein levels of SOX6 were detected using reverse transcription-quantitative polymerase chain reaction and western blotting. Vector and SCR were used as controls. (B) U2OS cells were transfected with vector or SOX6, SCR or \#2 SOX6 siRNA. Following transfection for $48 \mathrm{~h}$, a wound healing assay was used to determine the effect of SOX6 on cell migration. (C) U2OS cells were transfected with vector or SOX6, SCR or siSOX6. Following transfection for $48 \mathrm{~h}$, Transwell assays were used to determine the effect of SOX6 on cell invasion. "P<0.05; ** $\mathrm{P}<0.01$. SCR, scrambled small interfering RNA; siRNA, small interfering RNA; SOX6, transcription factor SOX6; siSOX6, siRNA\#1 and 2 (magnification, $x 40$ ).

$30 \mathrm{sec}, 58^{\circ} \mathrm{C}$ for $30 \mathrm{sec}$ and $72^{\circ} \mathrm{C}$ for $1 \mathrm{~min}$. The following primer sequences were used: Twist1 forward, 5'-AAGGGATGGACC TGAAACGG-3'; reverse, 5'-GGCAAACTGGAAGCAGCA AA-3; Snail forward, 5'-GAAGGAACGGGTGCTCTTGG-3'; reverse, 5'-TGGCATTGACGAGGGAAACG-3. Slug forward, 5'-CTGGATTATGCCTCTGTGAT-3'; reverse, 5'-TGGTAT TTATTTGCTGGTAG-3'.

Dual-luciferase activity assay. The promoter region (-2000 to +200) of TWIST1 was amplified and sub-cloned into the pGL-3 basic vector (Promega Corporation, Madison, WI, USA). Subsequently, plasmids were transfected into U2OS cells along with vector $(2 \mu \mathrm{g})$ or SOX6 $(0.5,1$ or $2 \mu \mathrm{g})$ using
Lipofectamine ${ }^{\circledR} 2000$ (Invitrogen; Thermo Fisher Scientific, Inc.), following the manufacturer's protocol. In addition, the Renilla gene was co-transfected as an internal control. Following transfection for $24 \mathrm{~h}$, the cells were lysed and the dual-luciferase reporter assay was conducted using the dual-luciferase assay system (Promega Corporation), according to the manufacturer's protocol. All assays were performed in triplicate.

Statistical analysis. All statistical analyses were performed with SPSS 18.0 software (SPSS, Inc, Chicago, IL, USA). The results of experiments are presented as the mean \pm standard deviation. Kaplan-Meier analysis followed by log-rank test 
A
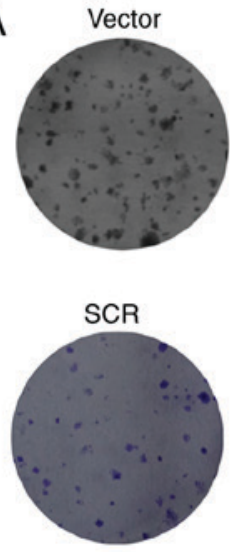

B

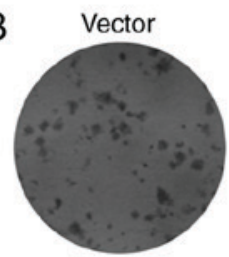

SCR

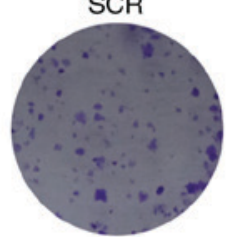

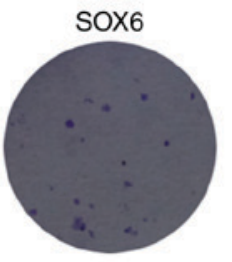
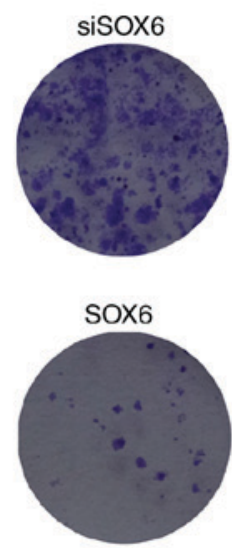

sisOX6

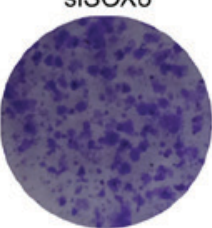

U2OS

C

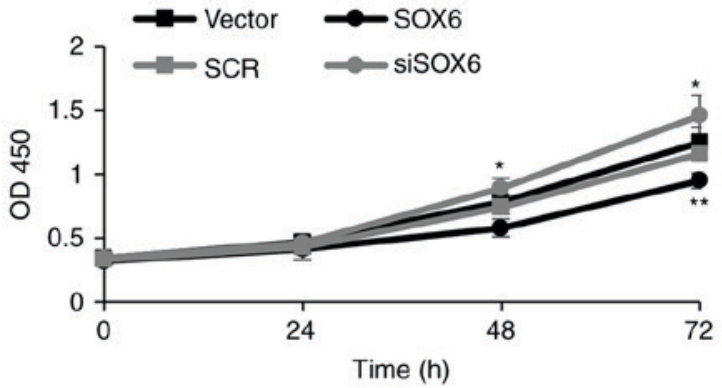

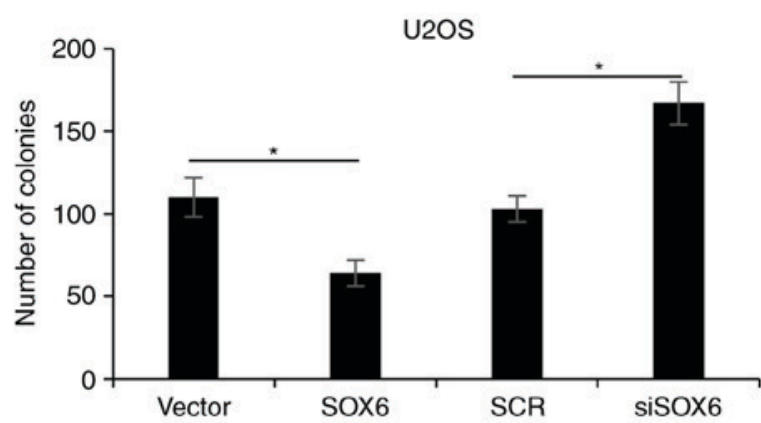

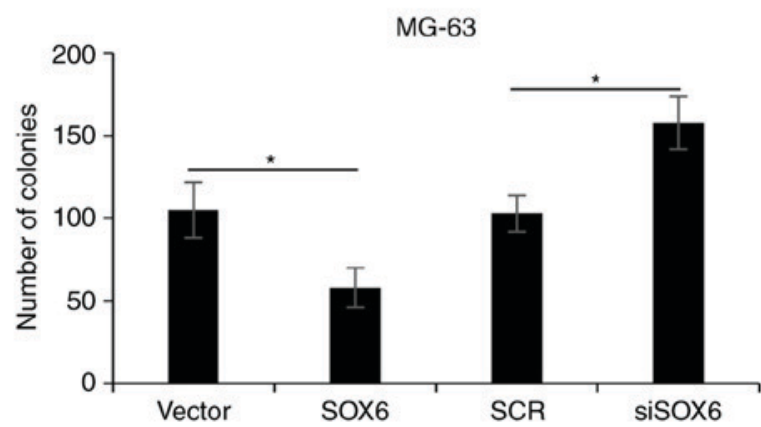

D

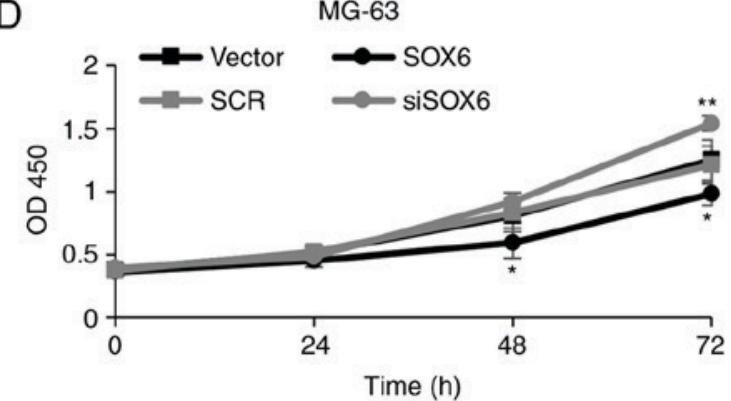

Figure 3. Modulation of SOX6 expression in osteosarcoma cells impacts upon their proliferation. (A) U2OS cells and (B) MG-63 cells were transfected with vector or SOX6, SCR or siSOX6. Following transfection for $48 \mathrm{~h}$, a colony formation assay was used to determine the effect of SOX6 on cell proliferation. ${ }^{*} \mathrm{P}<0.05$. (C) U2OS cells were transfected with vector or SOX6, SCR or siSOX6. Following transfection for $48 \mathrm{~h}$, cell viability was measured on the indicated days using the CCK-8 assay. (D) MG-63 cells were transfected with vector or SOX6, SCR or siSOX6. Following transfection for 48 h, cell viability was measured on the indicated days using the CCK-8 assay. ${ }^{*} \mathrm{P}<0.05 ;{ }^{* *} \mathrm{P}<0.01$ vs. vector group. CCK- 8 , cell counting kit- 8 ; SCR, scrambled short interfering RNA; SOX6, transcription factor SOX6; siSOX6, siRNA\#1 and 2.

was used to analyze the correlation between SOX6 expression and survival. The differences between two groups were determined with a Student's t-test. One-way analysis of variance followed by Tukey's test was used to analyze the differences between multiple groups. $\mathrm{P}<0.05$ was considered to indicate a statistically significant difference.

\section{Results}

SOX6 is frequently downregulated in OS tissues and cell lines. To investigate the function of SOX6 in OD, the expression of SOX6 in OS cell lines, MG-63 and U2OS, was analyzed via RT-qPCR and western blotting; the osteoblast cell line hFOB1.19 was used as a control group. The results of the present study demonstrated that the expression levels of SOX6 in MG-63 and U2OS cells were markedly lower compared with in hFOB1.19 cells $(\mathrm{P}<0.05$; Fig. 1A). Subsequently, the downregulation of SOX6 expression levels within OS tissues was determined by RT-qPCR using a total of 42 pairs of OS tissues and adjacent normal tissues. As presented in Fig. 1B, similar to the expression in cells, SOX6 was downregulated in OS tissues compared with normal tissues $(\mathrm{P}<0.05)$. Analysis of SOX6 expression levels and patient clinical information revealed that low expression levels of SOX6 were associated with the development of tumor metastasis. In addition, the expression of SOX6 was associated with tumor size and tumor stage (Table I). Subsequently, the correlation between SOX6 expression and survival was analyzed using a survival curve, 
A

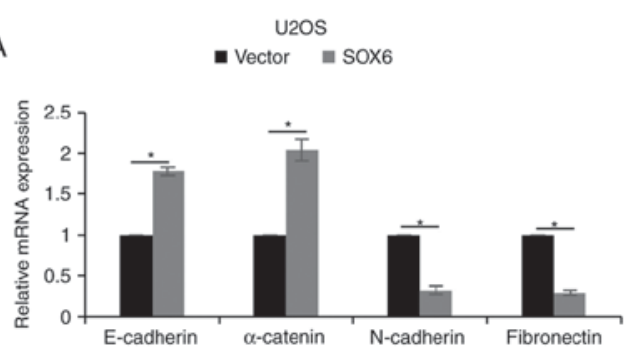

B

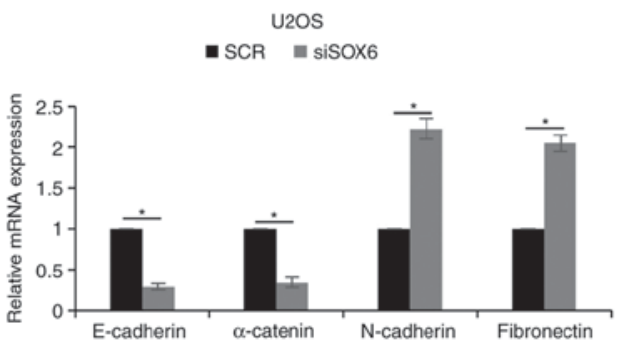

C

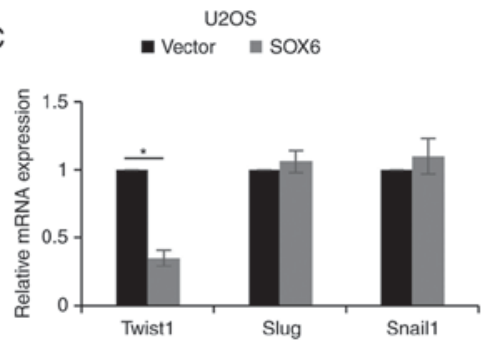

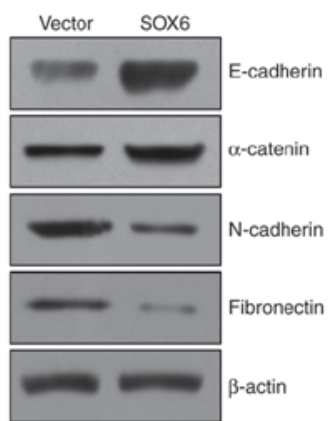

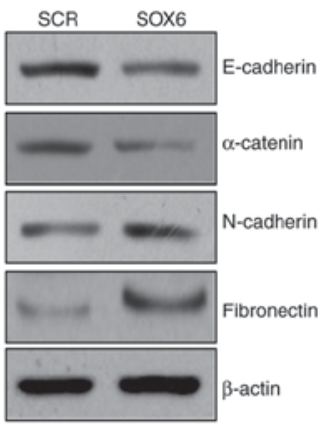

U2OS

D
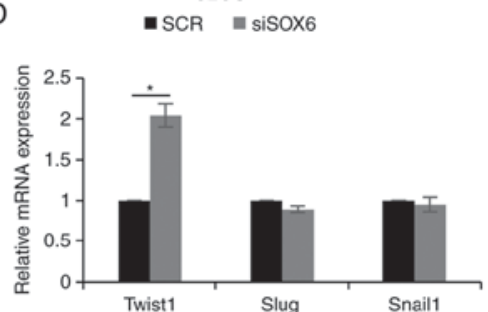

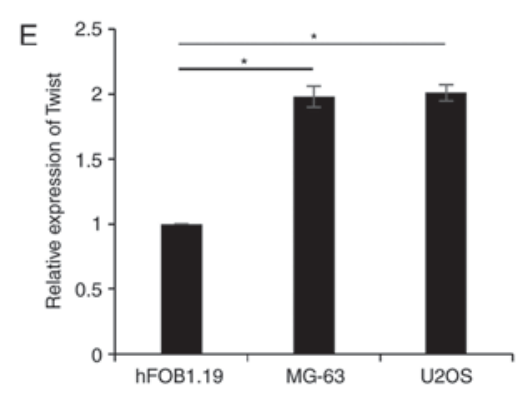

Figure 4. SOX6 suppresses EMT in osteosarcoma cells via the regulation of TWIST1. (A) SOX6 was overexpressed in U2OS cells. Following transfection for $48 \mathrm{~h}$, the expression of epithelial markers and mesenchymal markers was detected by RT-qPCR and western blotting. (B) SOX6 was knocked down in U2OS cells. Following transfection for $48 \mathrm{~h}$, the expression of epithelial markers and mesenchymal markers was detected by RT-qPCR and western blotting. (C) SOX6 was overexpressed in U2OS cells. Following transfection for $48 \mathrm{~h}$, the expression of EMT-associated transcription factors was detected by RT-qPCR. (D) SOX6 was knocked down in U2OS cells. Following transfection for $48 \mathrm{~h}$, the expression of EMT-associated transcription factors was detected RT-qPCR (E) The expression of TWIST1 in human osteosarcoma cell lines MG-63 and U2OS, and the normal osteoblastic cell line hFOB 1.19, was detected using RT-qPCR. "P<0.05. EMT, epithelial-mesenchymal transition; RT-qPCR, reverse transcription-quantitative polymerase chain reaction; SCR, scrambled short interfering RNA; SOX6, transcription factor SOX6; siSOX6, short interfering RNA\#1 and 2; Slug, zinc finger protein SNAI2; Snail1, zinc finger protein SNAI1; TWIST1, twist-related protein 1.

which revealed that patients with low expression levels of SOX6 had a poor prognosis $(\mathrm{P}<0.05$; Fig. $1 \mathrm{C})$.

Downregulation of SOX6 facilitates migration and invasion in U2OS. As presented in Table I, SOX6 may suppress the migratory and invasive abilities of OS cells. This was verified via the overexpression and silencing of SOX6 within U2OS cells expressing the plasmid pcDNA3.1-SOX6 or SOX6 siRNA, respectively. Western blotting and RT-qPCR were used to demonstrate SOX6 expression $(\mathrm{P}<0.05, \mathrm{P}<0.001$; Fig. 2A). The
siSOX6\#2 was more efficiency than siSOX6\#1, so siSOX6\#2 was used for subsequent experiments. Wound healing analysis was performed to detect the effects of SOX6 on cell migration, which revealed that the ectopic expression of SOX6 markedly reduced the migratory ability of U2OS cells; however, the inhibition of SOX6 significantly improved the migratory ability of U2OS cells $(\mathrm{P}<0.05$; Fig. $2 \mathrm{~B})$. In addition, the Transwell assay demonstrated that overexpression of SOX6 markedly decreased the number of invaded cells, and the inhibition of SOX6 markedly increased the number of invasive 

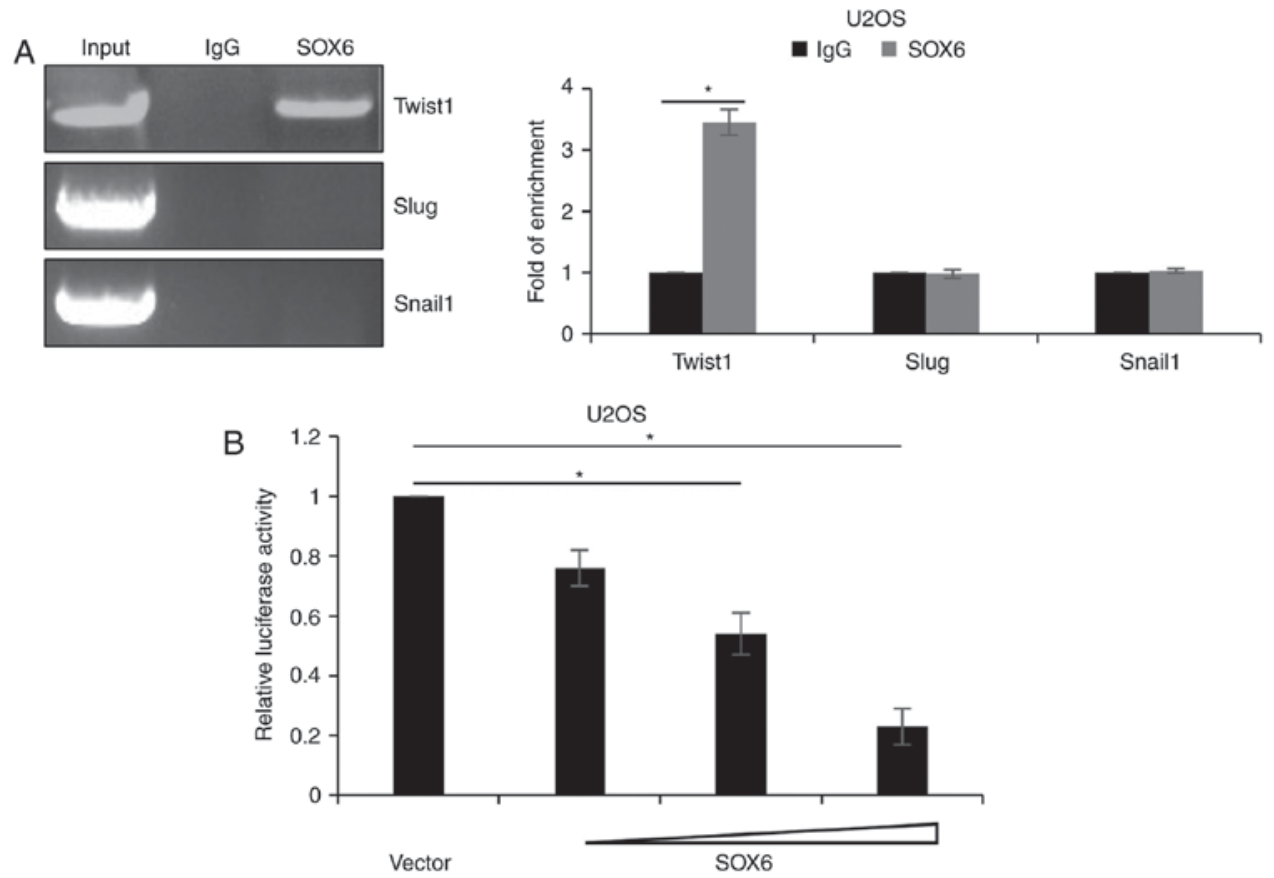

Figure 5. SOX6 transcriptionally regulates TWIST1 in osteosarcoma cells. (A) ChIP and quantitative ChIP analysis was used to detect whether SOX6 bound to the promoter region of TWIST1 in U2OS cells. (B) A dual luciferase activity assay was performed to determine the effect of SOX6 on the transcriptional regulation of TWIST1. "P<0.05. ChIP, chromatin immunoprecipitation; IgG, immunoglobulin G; SOX6, sex determining region Y-box protein 6; TWIST1, twist-related protein 1; Slug, zinc finger protein SNAI2; Snail1, zinc finger protein SNAI1; IgG, immunoglobulin G.

cells $(\mathrm{P}<0.05, \mathrm{P}<0.01$; Fig. $2 \mathrm{C})$. Therefore, the findings of the present study suggested that the downregulation of SOX6 facilitated migration and invasion of U2OS cells.

Modulation of SOX6 expression within OS cells affects cell proliferation. As presented in Table I, the expression of SOX6 was associated with tumor size. In the present study, the effects of SOX6 on cell proliferation were investigated via colony formation and CCK- 8 assays. The results of the colony formation assay revealed that the ectopic expression of SOX6 notably decreased the number of U2OS colonies compared with the control. Conversely, the inhibition of SOX6 expression markedly increased the number of colonies compared with the control $(\mathrm{P}<0.05$; Fig. $3 \mathrm{~A})$. Similar results were observed within MG-63 cells ( $\mathrm{P}<0.05$; Fig. 3B). Additionally, CCK-8 analysis illustrated that the overexpression of SOX6 reduced cell proliferation and that the inhibition of SOX6 increased the proliferative abilities of U2OS and MG-63 cells $(\mathrm{P}<0.05, \mathrm{P}<0.01$; Fig. $3 \mathrm{C}$ and $\mathrm{D})$. These results indicated that the modulation of SOX6 expression within OS cells affected proliferation.

SOX6 suppresses EMT of OS cells via the regulation of TWIST1. Previous reports have demonstrated that EMT promotes cancer development via migration and invasion (24); SOX5, in addition to SOX9, has been reported to regulate EMT $(25,26)$. To determine whether SOX6 suppressed the migration and invasion of U2OS cells via EMT regulation, markers of EMT were detected following the overexpression or downregulation of SOX6 in U2OS cells.

As presented in Fig. 4A, the mRNA and protein expression levels of mesenchymal markers, including $\mathrm{N}$-cadherin and fibronectin, were significantly decreased when SOX6 was overexpressed, although the expression of epithelial markers, including E-cadherin and $\alpha$-catenin, was significantly increased $(\mathrm{P}<0.05)$. However, inhibition of SOX6 significantly downregulated the expression of mesenchymal markers and upregulated epithelial marker expression levels $(\mathrm{P}<0.05$; Fig. 4B). To further investigate the underlying mechanism of EMT modulation via SOX6, the expression levels of EMT-associated transcription factors, including TWIST1, zinc finger protein SNAI2 (Slug) and zinc finger protein SNAI1 (Snail1) were analyzed. The results of the present study revealed the SOX6 exerted little effect on the expression levels of Slug and Snail1; however, the expression of TWIST1 was regulated by SOX6 $(\mathrm{P}<0.05$; Fig. $4 \mathrm{C}$ and D). Additionally, the expression of TWIST1 was detected in MG-63 and U2OS cells using RT-qPCR analysis; the osteoblast cell line hFOB1.19 served as the control. The results of the present study revealed that the expression levels of TWIST1 were upregulated within MG-63 and U2OS cells $(\mathrm{P}<0.05$; Fig. 4E); therefore, SOX6 may regulate EMT via TWIST1 modulation.

SOX6 transcriptionally regulates TWIST1 in OS cells. As SOX6 serves as a transcription factor, whether SOX6 is transcriptionally regulated was investigated. Chromatin immunoprecipitation (ChIP) and quantitative ChIP analysis was used to determine whether SOX6 bound to the promoter region of TWIST1. The results of the present study revealed that SOX6 directly bound to the promoter region of TWIST1 $(\mathrm{P}<0.05$; Fig. 5A). Subsequently, a dual luciferase activity assay was performed, which revealed that transfection with SOX6 markedly decreased the luciferase activity of the pGL3-TWIST1 group ( $\mathrm{P}<0.05$; Fig. 5B); therefore, SOX6 may have transcriptionally inhibited TWIST1. 


\section{Discussion}

Numerous reports have reported that SOX6 is downregulated in a number of types of cancer and acts as a tumor suppressor (18-20). However, the underlying mechanism of SOX6 in OS requires further investigation. The present study reported that the SOX6 expression levels were notably downregulated in OS, which was negatively-associated with tumor size, metastasis and tumor, node, metastasis stages. In addition, patients with low expression levels of SOX6 exhibited poor prognosis.

In the present study, numerous functional experiments, including a wound healing assay and a Transwell assay were performed to detect the effects of SOX6 on cell migration and invasion. The results suggested that SOX6 suppressed the migration and invasion of OS cells. EMT is a complex cellular process that has been associated with cancer migration and invasion (24). To improve understanding of the underlying mechanism of SOX6 in OS cell migration and invasion, SOX6-mediated regulation of EMT was investigated. The results of the present study revealed that the ectopic expression of SOX6 reduced the expression of mesenchymal markers, N-cadherin and fibronectin; however, the expression of epithelial markers, E-cadherin and $\alpha$-catenin, were increased. In addition, SOX6 inhibition increased the expression of mesenchymal markers, $\mathrm{N}$-cadherin and fibronectin, whereas the expression of epithelial markers, E-cadherin and $\alpha$-catenin, was decreased. EMT is regulated by a variety of transcription factors, including Snail1, TWIST1, Slug and zinc finger E-box-binding homeobox 1 (27-30). ChIP and qChIP analysis, and the dual-luciferase activity assay, demonstrated that SOX6 transcriptionally suppressed TWIST1. Further investigation is required to elucidate the detailed binding site of SOX6 on the TWIST1 promoter, which may require interactions with unknown proteins. Therefore, the results of the present study demonstrated that, SOX6 suppressed EMT via the regulation of TWIST1 in OS.

Previous studies have reported that SOX6 suppresses cell proliferation by transcriptionally suppressing cyclin D1 in pancreatic $\beta$-cells (23) or transcriptionally activating SOCS3 in primary erythroid cells (22). Additionally, numerous microRNAs promote cell proliferation by targeting SOX6 (31,32); however, further investigation is required to understand whether SOX6 may suppress cell proliferation in OS. The present study reported that the expression of SOX6 was negatively correlated with tumor size. A colony formation assay and a CCK-8 assay revealed that SOX6 additionally inhibited cell proliferation in OS; however, the underlying mechanism is yet to be investigated.

In the present study, SOX6 expression levels were downregulated in OS, indicating the tumor-suppressing roles of SOX6; low expression levels were associated with poor prognosis in OS. Additionally, SOX6 inhibited cell proliferation in OS cells, which suggested the potential role of SOX6 as a biomarker for OS.

\section{References}

1. Bielack SS: Osteosarcoma: Time to move on? Eur J Cancer 46: 1942-1945, 2010.

2. Cheng DD, Yu T, Hu T, Yao M, Fan CY and Yang QC: MiR-542-5p is a negative prognostic factor and promotes osteosarcoma tumorigenesis by targeting HUWE1. Oncotarget 6: 42761-42772, 2015.
3. Wagle S, Park SH, Kim KM, Moon YJ, Bae JS, Kwon KS, Park HS, Lee H, Moon WS, Kim JR and Jang KY: DBC1/CCAR2 is involved in the stabilization of androgen receptor and the progression of osteosarcoma. Sci Rep 5: 13144, 2015.

4. Damron TA, Ward WG and Stewart A: Osteosarcoma, chondrosarcoma and Ewing's sarcoma: National Cancer Data Base Report. Clin Orthop Relat Res 459: 40-47, 2007.

5. Byun BH, Kong CB, Lim I, Kim BI, Choi CW, Song WS, Cho WH, Jeon DG, Koh JS, Lee SY and Lim SM: Comparison of (18)F-FDG PET/CT and (99 m)Tc-MDP bone scintigraphy for detection of bone metastasis in osteosarcoma. Skeletal Radiol 42: 1673-1681, 2013

6. Dirik Y, Çınar A, Yumrukçal F and Eralp L: Popliteal lymph node metastasis of tibial osteoblastic osteosarcoma. Int J Surg Case Rep 5: 840-844, 2014.

7. Yanagawa T, Saito K and Takagishi K: Risk factors for lymphatic metastasis of malignant bone and soft-tissue tumors: A retrospective cohort study of 242 patients. Medicine (Baltimore) 93: e225, 2014.

8. Zhu H, Tang J, Tang M and Cai H: Upregulation of SOX9 in osteosarcoma and its association with tumor progression and patients' prognosis. Diagn Pathol 8: 183, 2013.

9. Bi Y, Jing Y and Cao Y: Overexpression of miR-100 inhibits growth of osteosarcoma through FGFR3. Tumour Biol 36: 8405-8411, 2015.

10. Wang W, Zhou X and Wei M: MicroRNA-144 suppresses osteosarcoma growth and metastasis by targeting ROCK 1 and ROCK2. Oncotarget 6: 10297-10308, 2015.

11. Rainusso N, Wang LL and Yustein JT: The adolescent and young adult with cancer: State of the art-bone tumors. Curr Oncol Rep 15: 296-307, 2013.

12. Gorlick R, Anderson P, Andrulis I, Arndt C, Beardsley GP, Bernstein M, Bridge J, Cheung NK, Dome JS, Ebb D, et al: Biology of childhood osteogenic sarcoma and potential targets for therapeutic development: Meeting summary. Clin Cancer Res 9: 5442-5453, 2003 .

13. Kager L, Zoubek A, Pötschger U, Kastner U, Flege S, Kempf-Bielack B, Branscheid D, Kotz R, Salzer-Kuntschik M, Winkelmann W, et al: Primary metastatic osteosarcoma: Presentation and outcome of patients treated on neoadjuvant cooperative osteosarcoma study group protocols. J Clin Oncol 21: 2011-2018, 2003.

14. Wan J, Zhang X, Liu T and Zhang X: Strategies and developments of immunotherapies in osteosarcoma. Oncol Lett 11: 511-520, 2016.

15. Kamachi Y and Kondoh H: Sox proteins: Regulators of cell fate specification and differentiation. Development 140: 4129-4144, 2013.

16. Wegner M: From head to toes: The multiple facets of Sox proteins. Nucleic Acids Res 27: 1409-1420, 1999.

17. Bowles J, Schepers G and Koopman P: Phylogeny of the SOX family of developmental transcription factors based on sequence and structural indicators. Dev Biol 227: 239-255, 2000.

18. Xie Q, Chen X, Lu F, Zhang T, Hao M, Wang Y, Zhao J, McCrae MA and Zhuang H: Aberrant expression of microRNA 155 may accelerate cell proliferation by targeting sex-determining region Y box 6 in hepatocellular carcinoma. Cancer 118: 2431-2442, 2012

19. Guo X, Yang M, Gu H, Zhao J and Zou L: Decreased expression of SOX6 confers a poor prognosis in hepatocellular carcinoma. Cancer Epidemiol 37: 732-736, 2013.

20. Qin YR, Tang H, Xie F, Liu H, Zhu Y, Ai J, Chen L, Li Y, Kwong DL, Fu L and Guan XY: Characterization of tumor-suppressive function of SOX6 in human esophageal squamous cell carcinoma. Clin Cancer Res 17: 46-55, 2011.

21. Cantù C, Ierardi R, Alborelli I, Fugazza C, Cassinelli L, Piconese S, Bosè F, Ottolenghi S, Ferrari G and Ronchi A: Sox6 enhances erythroid differentiation in human erythroid progenitors. Blood 117: 3669-3679, 2011.

22. Iguchi H, Urashima Y, Inagaki Y, Ikeda Y, Okamura M, Tanaka T, Uchida A, Yamamoto TT, Kodama T and Sakai J: SOX6 suppresses cyclin D1 promoter activity by interacting with beta-catenin and histone deacetylase 1 , and its down-regulation induces pancreatic beta-cell proliferation. J Biol Chem 282: 19052-19061, 2007.

23. Livak KJ and Schmittgen TD: Analysis of relative gene expression data using real-time quantitative PCR and the 2(-Delta Delta C(T)) method. Methods 25: 402-408, 2001. 
24. Sannino G, Armbruster N, Bodenhöfer M, Haerle U, Behrens D, Buchholz M, Rothbauer U, Sipos B and Schmees C: Role of BCL9 $\mathrm{L}$ in transforming growth factor- $\beta$ (TGF- $\beta$ )-induced epithelial-to-mesenchymal-transition (EMT) and metastasis of pancreatic cancer. Oncotarget 7: 73725-73738, 2016.

25. Wang D, Han S, Wang X, Peng R and Li X: SOX5 promotes epithelial-mesenchymal transition and cell invasion via regulation of Twistl in hepatocellular carcinoma. Med Oncol 32: 461, 2015.

26. Huang J and Guo L: Knockdown of SOX9 Inhibits the Proliferation, Invasion, and EMT in Thyroid Cancer Cells. Oncol Res 25: 167-176, 2017.

27. Medici D, Hay ED and Olsen BR: Snail and Slug promote epithelial-mesenchymal transition through beta-catenin-T-cell factor-4-dependent expression of transforming growth factor-beta3. Mol Biol Cell 19: 4875-4887, 2008.

28. Alves CC, Carneiro F, Hoefler H and Becker KF: Role of the epithelial-mesenchymal transition regulator Slug in primary human cancers. Front Biosci (Landmark Ed) 14: 3035-3050, 2009.
29. Kojc N, Zidar N, Gale N, Poljak M, Fujs Komlos K, Cardesa A, Höfler H and Becker KF: Transcription factors Snail, Slug, Twist, and SIP1 in spindle cell carcinoma of the head and neck. Virchows Arch 454: 549-555, 2009.

30. Preca BT, Bajdak K, Mock K, Lehmann W, Sundararajan V, Bronsert P, Matzge-Ogi A, Orian-Rousseau V, Brabletz S, Brabletz T, et al: A novel ZEB1/HAS2 positive feedback loop promotes EMT in breast cancer. Oncotarget 8: 11530-11543, 2017.

31. Li Z and Wang Y: MiR-96 targets SOX6 and promotes proliferation, migration and invasion of hepatocellular carcinoma. Biochem Cell Biol: July 17, 2017 doi: 10.1139/bcb-2017-0183. (Epub ahead of print)

32. Li YC, Li CF, Chen LB, Li DD, Yang L, Jin JP and Zhang B: MicroRNA-766 targeting regulation of SOX6 expression promoted cell proliferation of human colorectal cancer. Onco Targets Ther 8: 2981-2988, 2015. 